\title{
Uma estratégia de desenvolvimento para o sistema nacional de inovação de produtos médicos
}

\author{
Vera Lúcia da Silveira Nantes Button*, Eduardo Jorge Valadares Oliveira
}

Resumo O presente trabalho apresenta a proposta de um Programa para o desenvolvimento do Sistema Nacional de Inovação de Produtos Médicos - SNIPM no âmbito do Sistema Único de Saúde - SUS, de forma integrada e alinhada com as ações do Ministério da Saúde. Os conhecimentos e as ferramentas em engenharia clínica permitiram realizar uma análise diferenciada do contexto socioeconômico do setor, a sistematização e a percepção dos fatores e atores que induzem ou retardam o crescimento tecnológico do setor. Neste artigo, buscou-se contextualizar o setor de produtos médicos no Brasil à luz da atual conjuntura socioeconômica nacional e mundial, caracterizando-o como de grande indutor de atividades inovadoras. Posteriormente, são abordadas as definições e teorias sobre os Sistemas Nacionais de Inovação e as especificidades do SNIPM no Brasil, apresentando seus atores incluindo suas atribuições e competências. A metodologia utilizada para a coleta e análises de dados econômicos é apresentada, de modo a caracterizar a importância deste segmento para a economia nacional e suas potencialidades na indução do surgimento de tecnologias inovadoras no SNIPM. A análise dos dados setoriais coletados durante a pesquisa é apresentada, como o objetivo de quantificar e apresentar os números socioeconômicos do setor de produtos. Por fim, é apresentado o delineamento de um Programa destinado acatalisar o desenvolvimento do SNIPM considerando as demandas tecnológicas e prioridades do SUS e as dos mercados-alvo do setor produtivo. A proposta, que foi desenvolvida e implementada no Ministério da Saúde, pode se constituir como uma das ferramentas no âmbito do SUS destinadas a fortalecer e modernizar o setor de equipamentos e materiais de uso em saúde, visando à ampliação da capacidade inovadora das empresas e mudança do seu patamar competitivo.

Palavras-chave Sistema nacional de inovação, Engenharia clínica, Produtos médicos, Equipamentos médicos, Complexo industrial da saúde, Economia da saúde.

\section{A strategy for the development of the medical devices national innovation system}

\begin{abstract}
This paper presents a proposal of a program for the development of the Brazilian National Innovation System for Medical Products (SNIPM) under the National Health System (SUS) integrated and aligned with the actions of the Brazilian Ministry of Health. Clinical engineering knowledge and tools allowed performing a differentiated socio-economic analysis of the sector, the systematization and the perception of actors and factors that induce or retard the growth of the technology sector. In this article, the medical devices sector in Brazil was first contextualized to in the light of current national and global socio-economic conjuncture, in order to characterize it as a major inducer of innovative activities. The definitions and theories about the National Innovation Systems are described, followed by a discussion of the specifics of SNIPM in Brazil, with its actors, including their duties and responsibilities. The methodology for the collection and analysis of economic data, were shown, in order to characterize the importance of this sector to the national economy and its potential to induce the rising of innovative technologies whithin the SNIPM. The analysis of industry data is presented, which attempts to present and comment on some industry data collected during a survey. In the Results section, it is presented the design of a program used to to catalyze the development of the SNIPM considering the technological demands and priorities of the SUS and the target markets of the productive sector. The proposed program, which was developed and implemented within the Brazilian Ministry of Health, can become one of the tools within the SUS to strengthen and modernize the sector of medical equipments and materials, aiming to increase the innovative capacity of firms and change its competitive standing.
\end{abstract}

Keywords National innovation system, Clinical engineering, Medical devices, Medical equipment, Health industrial complex, Health economics.

*e-mail: vera@ceb.unicamp.br

Recebido: 15/08/2010 / Aceito: 07/02/2012 


\section{Extended Abstract}

\section{Introduction}

Health configures a complex set of productive activities of goods and services that leverages key segments of the modern society. Beyond its social dimension linked to citizenship, health has its own economic dimension, articulating public and private entities in a wide network of health care - through the Brazilian Unified Health System - SUS and the Brazilian Health Insurance System. It is a unique source of opportunity to promote national development in the context of the health policies and the National Productive Development Policy - PDP. The current political conjecture of the country aims to establish a long-term horizon in which the domestic industry falls in a technologically innovative context, establishing solid criteria for changing the production platform, innovation of products and industrial processes. In this context we can highlight the Innovation Law, the PDP mentioned above, and the program "More Health" instituted by the Brazilian Ministry of Health-MS, which establishes the Health Industrial Complex (HIC) as one of the priorities in order to promote economic and social development of the country.

In the same way that Clinical Engineering - CE addresses issues such as types and risks of medical technologies, working flows and administrative contribute helping in the definition of strategies to increase technological and development of the National Innovation System for Medical Products.

\section{The Brazilian Medical Devices Innovation System}

A National Innovation System - SNI can be defined as a network of public and private institutions that integrate their actions towards the promotion the scientific and technological development of a country. Among the actors of an innovation system, can be detached in the government: the foment institutions, regulatory agencies, and the scientific and technological institutions - ICT (e.g. Universities, Technology institutes, and technical schools); in the private sector: firms and class associations. Within the SNI the knowledge and innovation activities are considered crucial, and the productive sector its spine. However, it is not possible to innovate in an isolate process, for innovation is an interactive process and, in this way, it depends on the interaction between different actors and institutions. In the SNI, the knowledge diffusion is the key for innovation generation. Figure 1 shows the structure of the Brazilian Medical Devices Innovation System - SNIPM.

\section{Materials and Methods}

To justify a RD\&I policy in SUS, it was important to contextualize the medical device sector and show its social-economic impact in health sector. In SUS reimbursement model most medical devices are not directly included in the reimbursement list; the cost of these products occurs through re-payment of health services provisions. However products for particular patient (e.g. hearing aids, stents and orthopedic prostheses) are included. To map properly the sector economic conjuncture it was important to consider data from government agencies other than Ministry of Health, namely: Central Bank of Brazil-BaCen, Ministry of Development, Industry and Trade - MDIC, Ministry of Labor and Employment - MTE, National Bank for Economic and Social Development - BNDES, and the National Sanitary Surveillance Agency - ANVISA.

\section{Analysis of Sectorial Data}

The purpose of this topic is to present, quantify and analyze the socio-economic numbers of the medical devices sector. The article presents BNDES'data regarding the financing for the sector (Table 1), demonstrating that the major catchments of the industry are intended for production activities. The data regarding foreign direct investment (IED) shows that, between 2002 and 2006 this type of capital was responsible for most of the sectoral investments (Figure 2). Regarding laboring and employment, Figure 3 shows the distribution of educational level of workers and their average wages in this industry. The Brazilian trade balance data are presented in Figure 4, where, for the year 2006, the sector's trade deficit was over US\$1.1 billion. Regarding SUS expenditures and its impact on the medical devices market, it presents the data from the MS that reflects the direct costs with medical devices reimbursement and the medical equipment demands from the public and philanthropic services providers (Table 2). The topic is closed with the presentation of data from a survey made with the national manufacturers seeking the importance of technological cooperation between them and national research institutions and the relevance of the certification process for its business.

\section{Results}

The proposed action lines of "National Program for Qualification, Production and Innovation in Medical Devices within the Brazilian Health Industrial Complex" (Brasil, 2008c) (Portaria $\left.M S / G M n^{\circ} 375 / 2008\right)$, consist in horizontal actions within the program, whose central themes and approaches are presented in Figure 8. The main premise for the definition of those strategies for the program, and the establishment of projects and actions, is that those must be consistent and adhering to the health programs of the Ministry, particularly programs and projects developed and implemented by the Department of Health Care - SAS.

\section{Discussion and Conclusion}

In the presented scenario it is suggested that in SNIPM, the initial efforts in science, technology and innovation should be guided by the SUS in the light of its demands for goods and economic services, and the social and regional needs of the country.

It is also verified that the actual conjuncture of the SNIPM demands specialized technological services mainly those provided by clinical engineering. The diverse foment and financial policies created by the Brazilian Government places the clinical engineering as a strategic activity that will strengthen and modernize the sector of medical products. The proposed Program aims to the innovative capacity of the firms and change of its competitive level from the technological demands of the SUS and initiatives of articulation of public and private cooperative actions. 


\section{Introdução}

A saúde configura um complexo de atividades produtivas de bens e serviços que alavanca segmentoschave da sociedade contemporânea. Além de sua dimensão social vinculada à própria cidadania, a saúde possui uma dimensão econômica própria, articulando entidades públicas e privadas em uma ampla rede de assistência à saúde através do Sistema Único de Saúde - SUS e do Sistema Nacional de Saúde Suplementar (sistema de saúde que engloba os planos e seguradoras de saúde privados), além de um parque industrial responsável pelo fornecimento de uma vasta cadeia de produtos destinados aos cuidados da saúde humana. É uma fonte única de oportunidade para o desenvolvimento nacional no contexto das Políticas de Saúde e da Política de Desenvolvimento Produtivo - PDP. O Complexo Industrial e de Inovação em Saúde, componente do Sistema Nacional de Inovação de Produtos Médicos - SNIPM (Figura 1), incorpora setores industriais que se articulam com a rede nacional de serviços de saúde constituindo um conjunto altamente dinâmico de atividades econômicas que se relacionam com um padrão de desenvolvimento que pode associar crescimento econômico e equidade (Gadelha, 2003).
A atual conjuntura político institucional do país almeja estabelecer um horizonte de longo prazo no qual a indústria nacional se insira num contexto tecnologicamente inovador, estabelecendo critérios sólidos de mudança de patamar produtivo, inovação de produtos e processos industriais. Neste contexto destacam-se a "Lei do Bem" (Brasil, 2005) (Lei Federal $\mathrm{n}^{\circ} 11.196 / 2005$, que trata de incentivos fiscais para pessoas jurídicas que realizam pesquisa e desenvolvimento de inovação tecnológica e permite subvenções financeiras por parte de órgãos governamentais de fomento à pesquisa), a Lei da Inovação (Brasil, 2004) (Lei Federal no 10.973/2004, que dispõe sobre incentivos à inovação e à pesquisa científica e tecnológica no ambiente produtivo), a PDP já mencionada, e de modo extraordinário o Programa Mais Saúde do Ministério da Saúde que insere o Complexo Industrial da Saúde como um dos eixos de promoção do desenvolvimento socioeconômico do país.

A indústria de produtos médicos engloba uma grande variedade de produtos e tecnologias. Tomando-se como referência a Global Medical Device Nomenclature-GMDN, tem-se uma lista de mais de 8 mil nomes técnicos distintos. Estes se desdobram, de acordo com a Organização Mundial da Saúde - OMS,

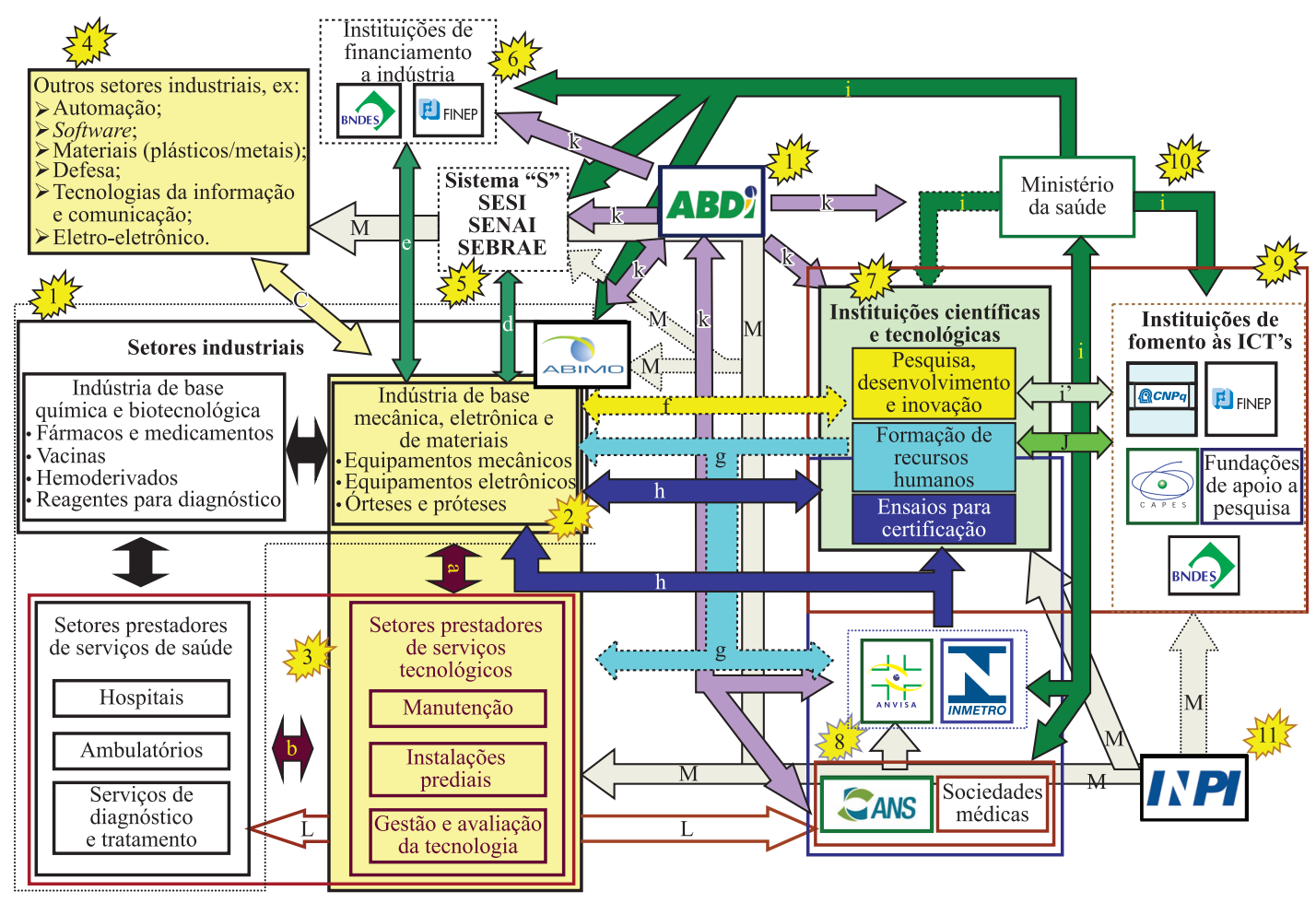

Figura 1. Atual conjuntura do Sistema Nacional de Inovação do setor de equipamentos e materiais de uso em saúde.

Figure 1. Present conjuncture of the Brazilian National Innovation System of medical devices. 
no ano de 2003, em cerca de 1,5 milhões de produtos diferentes (World..., 2003).

Os dados da OMS apontam ainda que em 2006 o mercado mundial de produtos médicos foi de aproximadamente US\$ 260 bilhões. Além disso, estudos conduzidos pela União Européia apontam uma taxa de crescimento anual de $16 \%$ para o mercado. Cinco países concentram cerca de $80 \%$ de todo o mercado mundial de produtos médicos: EUA, Japão, Alemanha, Holanda e França. Os Estados Unidos constituem o maior mercado mundial, representando de 43 a $48 \%$ do mercado, seguido pelo mercado Europeu (30 a 34\%). A América Latina representa de 3 a 5\% do mercado e o Brasil 1,2\% do mercado mundial, dependendo do produto (Oliveira et al., 2008).

A indústria de produtos médicos brasileira surgiu na década de 1950 e alcançou o seu ápice nos anos 1970. Nas últimas três décadas transformações nos cenários nacional e internacional trouxeram novos desafios ao setor. A abertura de mercado na década de 1990 esgotou o modelo formal de substituição de importações e reserva de mercado, promovendo o surgimento de um novo ambiente concorrencial ao setor. Além do mais, a regulação do mercado iniciada pelo Ministério da Saúde - MS (Brasil, 1993) (Portaria Conjunta $\mathrm{n}^{\circ} 01$ SNVS/SAS, de 17 de maio de 1993) e seus desdobramentos catalisados pela Agência Nacional de Vigilância Sanitária - ANVISA trouxe à tona novos conceitos e exigência de padrões mínimos de qualidade para as empresas.

É importante destacar que se por um lado novos fatores regulatórios-econômicos tornaram mais árdua a expansão do setor, por outro lado induziram uma significativa melhora na qualidade das tecnologias fabricadas no país. Isto é observado analisando-se os dados das edições de 2003, 2005 e 2007 da Pesquisa Industrial de Inovação Tecnológica - PINTEC, realizada pelo Instituto Brasileiro de Geografia e Estatística - IBGE, onde o setor de produtos médicos aparece como sendo um dos dez mais inovadores no país (Arruda et al., 2006). Neste período, novos conceitos regulatórios foram fortemente introduzidos no mercado: as Boas Práticas de Fabricação e Controle - BPFC e a Certificação Compulsória de equipamentos no âmbito do Instituto Nacional de Metrologia, Normalização e Qualidade Industrial - INMETRO.

Outro fato a ser observado é que a constante evolução tecnológica dos materiais e componentes utilizados na fabricação dos produtos médicos faz com que se tenha no mercado produtos com ciclo de vida cada vez mais curto, estimado em 18 a 24 meses (Bobbie, 2010). Isto traz duas consequências, a primeira é a de que, para os produtos de alta tecnologia, é muito provável que ocorra obsolescência antes de se conhecer todos os seus potenciais benefícios ou malefícios. A segunda é que muitas empresas estão deixando de patentear seus produtos, o que causa resultados negativos na avaliação de seus bens intangíveis.

Esta dinâmica na evolução tecnológica do setor aliada à defasagem tecnológica verificada no país $\mathrm{e}$, consequentemente, à enorme dependência de importações, configura uma situação de vulnerabilidade para o SUS que pode ser extremamente danosa para o bem-estar da população. Os programas de assistência médica (que utilizam dispositivos diagnósticos, equipamentos médicos, órteses, próteses e outras tecnologias) entre outros, não podem ficar sujeitos às oscilações do mercado financeiro internacional e reféns de estratégias competitivas descoladas do interesse nacional.

Neste contexto existe uma possibilidade de se utilizar os conhecimentos da engenharia clínica não só no nível microeconômico dos sistemas de saúde (ex. hospitais, clínicas ou postos de saúde, indústrias e comércio), mas também no nível macroeconômico (ex. definição de instrumentos e políticas públicas). Estes conhecimentos possibilitam auxiliar em atividades de planejamento, programas para incorporação de tecnologias para a saúde e na definição e execução de políticas públicas.

Esta visão diferenciada permite que a engenharia clínica tenha papel singular em órgãos regulatórios (ANVISA e INMETRO), órgãos normalizadores (Associação Brasileira de Normas Técnicas - ABNT), órgãos normativos (MS, Conselho Nacional de Saúde - CNS, Secretarias Estaduais de Saúde - SES, órgãos de classe profissionais) ou financiadores (agentes de fomento, planos e seguro de saúde, etc.). Ademais, as peculiaridades do SNIPM fazem com que uma proposta indutora para seu desenvolvimento não possa adotar modelos unicamente econômicos sem que se avalie o contexto regulatório, científico e as demandas tecnológicas do SUS.

\section{O Sistema Nacional de Inovação}

Um Sistema Nacional de Inovação - SNI pode ser definido como uma rede de instituições públicas e privadas que interagem para promover o desenvolvimento científico e tecnológico de um país (Freeman, 1988). Dentre os atores de um sistema de inovação pode-se destacar no governo: as agências de fomento e reguladoras; as Instituições Científicas e Tecnológicas - ICTs (ex. universidades, institutos de tecnologia e escolas técnicas), conforme definidos pela Lei da Inovação; no setor privado: as empresas - e no caso do setor de equipamentos e materiais de uso em saúde incluem-se firmas dos mais variados 
segmentos - e as associações e organizações da sociedade civil e entidades de classe.

O grande mérito dos atuais conceitos de SNI é o de não limitar a atividade inovadora ou o desenvolvimento tecnológico às atividades de $\mathrm{P} \& \mathrm{D}$ realizadas no âmbito do setor produtivo, mas sim como uma relação dinâmica que abarca diversos atores heterogêneos, dotados de distintas competências, motivações e padrões organizacionais. Outro fator importante é que a tecnologia não é apenas desenvolvida, mas também difundida e incorporada na sociedade, demonstrando que a evolução tecnológica transcende o progresso técnico, na medida em que agrega outros elementos como as mudanças na conjuntura político-institucional e a forma como agentes interagem entre si. Esta assertiva alinha-se com o descrito por Rosenberg (1982), que apresenta um cenário onde o processo de inovação não decorre de um único agente, mas é fruto de um aprendizado coletivo, interativo e dinâmico.

\section{O Sistema Nacional de Inovação de Produtos Médicos - SNIPM}

Na Figura 1 tem-se o SNIPM do Brasil, onde os diversos vínculos entre os atores são descritos como segue. Na estrela 1 tem-se o conceito de Complexo Industrial da Saúde apresentando por Gadelha (2003) onde atividades produtivas estão inseridas num contexto político e institucional bastante particular, envolvendo a prestação de serviços de saúde como o espaço econômico para o qual flui toda a produção. Em 2 tem-se as firmas de produtos médicos as quais se relacionam mais fortemente com os setores prestadores de serviços de saúde - PSS no início do processo de comercialização de um produto. Em um segundo momento, entra na relação com os PSS o setor prestador de serviços tecnológicos - PST, destinado a realizar atividades de manutenção preventiva e corretiva em equipamentos e instalações e, em alguns casos, gerenciar processos de avaliação tecnológica (seta a). Em 3 verifica-se que após o processo de venda, o setor prestador de serviços passa a ofertar/demandar produtos e serviços dos fabricantes, e também oferta produtos e serviços aos estabelecimentos de saúde (seta b).

Destaca-se que nenhuma das inovações no setor de produtos médicos é consequência automática de avanços exclusivos desta área do conhecimento (estrela 4, seta c). O desenvolvimento de inovações em produtos médicos resulta predominantemente de processos incrementais. Nestes processos, o envolvimento de profissionais de saúde é crucial para identificar a necessidade de um novo equipamento, definir sua indicação e finalidade, estabelecer requisitos de segurança e eficácia, participar na construção de protótipos e para aprimoramentos decisivos para o desenvolvimento do equipamento. Ou seja, o processo de inovação ocorre não apenas nos laboratórios industriais, mas também nos estabelecimentos de saúde (Albuquerque e Cassiolato, 2002).

O Sistema "S", que aparece na estrela 5 , se constitui em um conjunto de "Serviços Sociais Autônomos - SSA" (sistema composto por instituições caracterizadas pela prestação de atividade de interesse público, não exclusiva do Estado, autorizada em lei e sem fins lucrativos, sob o regime de Direito Privado como, por exemplo, o Serviço Brasileiro de Apoio às Micro e Pequenas Empresas - SEBRAE, Serviço Nacional de Aprendizagem Industrial - SENAI, etc.) que prestam um importante suporte a firmas do setor na qualificação de pessoal, cursos técnicos especializados, treinamento em gestão empresarial e promoção de projetos objetivando o adensamento de cadeias produtivas e promoção empresarial.

Os dois principais agentes de financiamento e fomento do setor aparecem na estrela 6. O Banco Nacional de Desenvolvimento Econômico Social - BNDES que disponibiliza linhas de crédito específicas para o setor industrial, com taxas de juros diferenciadas e condições de pagamento de longo prazo. A Financiadora de Estudos e Projetos - FINEP insere-se tanto no financiamento às empresas com linhas de crédito como o "Juro Zero" e o "Pró-Inovação", quanto no fomento via encomendas tecnológicas e pela subvenção econômica.

Em 7 encontra-se as Instituições Científicas e Tecnológicas - ICTs. Na seta f tem-se a oferta e demanda de processos de PD\&I, onde há uma fragilidade importante na relação entre setor produtivo e as ICTs. Na seta g tem-se a oferta e a demanda de recursos humanos qualificados. Entretanto não se observa uma relação consolidada entre o perfil profissional demandado pelo setor produtivo e o disponibilizado pelas Instituições. Nas relações entre empresas e ICTs a mais estruturada está diretamente relacionada com as demandas regulatórias da ANVISA e do INMETRO (estrela 8) que coordenam e definem o modus operandi do sistema de certificação compulsória de produtos médicos. Ainda na estrela 8 é possível verificar a existência de outros órgãos reguladores, como a Agência Nacional de Saúde Suplementar - ANS e as sociedades médicas (destaque no bloco marrom e seta L), que controlam a prestação dos serviços de saúde e cuja atuação pode influenciar as estratégias de produção das indústrias de produtos médicos como, por exemplo, as decisões sobre inclusão ou exclusão de tecnologias em procedimentos médicos cobertos por planos de saúde.

$\mathrm{Na}$ estrela 9 aparecem as tradicionais agências de fomento às ICTs, o Conselho Nacional de 
Desenvolvimento Científico e Tecnológico - CNPq (fundação pública vinculada ao Ministério da Ciência e Tecnologia), a FINEP (empresa pública vinculada ao Ministério da Ciência e Tecnologia), a Coordenação de Aperfeiçoamento de Pessoal de Nível Superior - CAPES (fundação pública vinculada ao Ministério da Educação), as Fundações Estaduais de Amparo a Pesquisa - FAPs e o Fundo Tecnológico - FUNTEC do BNDES. Este último destina-se a apoiar financeiramente projetos que objetivam estimular o desenvolvimento tecnológico e a inovação de interesse estratégico para o país, em conformidade com os programas e políticas públicas do governo federal.

Em 10 tem-se o Ministério da Saúde (e outros ministérios como o Ministério da Ciência e Tecnologia e Ministério da Educação) aportando recursos nas agências de fomento, com exceção do BNDES, para apoio a programas e projetos de pesquisa específicos. $\mathrm{O}$ MS realiza também o fomento direto às ICTs para o desenvolvimento de estudos, projetos e encomendas tecnológicas. Destacam-se as ações da Secretaria de Ciência, Tecnologia e Insumos Estratégicos - SCTIE do MS que desenvolve diversas atividades de geração, difusão e aplicação de novos conhecimentos, buscando atender às necessidades do SUS e aproximar as inovações científicas e o desenvolvimento tecnológico das ações de prevenção e controle dos problemas de saúde da população brasileira.

O Instituto Nacional da Propriedade Industrial - INPI, estrela 11 e seta M, é uma autarquia federal vinculada ao Ministério do Desenvolvimento, Indústria e Comércio Exterior - MDIC, responsável por registros de marcas, concessão de patentes, averbação de contratos de transferência de tecnologia e de franquia empresarial, e por registros de programas de computador, desenho industrial e indicações geográficas, de acordo com a Lei de Propriedade Industrial (Brasil, 1996) (Lei no 9.279/1996, que regula direitos e obrigações relativos à propriedade industrial) e a Lei de Software (Brasil, 1998) (Lei no 9.609/1998, que dispõe sobre a proteção da propriedade intelectual de programa de computador, sua comercialização no País, e dá outras providências).

Quanto à sua inserção no SNIPM, o INPI atua junto a associações empresariais, federações, universidades, agências de desenvolvimento e o Sistema "S". Desde a sua reestruturação a partir de 2004, o Instituto atua ainda em atividades de capacitação empresarial em temas relacionados à propriedade intelectual. $\mathrm{O}$ mecanismo regulatório da propriedade intelectual se constitui como instrumento de capacitação e competitividade, condições fundamentais para alavancar o desenvolvimento tecnológico e econômico do país.

Por fim, na estrela 12 tem-se a Agência Brasileira de Desenvolvimento Industrial - ABDI. Esta Agência foi instituída em 2005 pelo Governo Federal, sob a figura de um Serviço Social Autônomo (SSA) com a competência de "promover a execução de políticas de desenvolvimento industrial, especialmente as que contribuam para a geração de empregos, em consonância com as políticas de comércio exterior e de ciência e tecnologia", ou seja, a Agência é responsável por articular os diversos atores do Estado responsáveis pelas ações de promoção do desenvolvimento econômico e industrial com o setor produtivo e sociedade civil (setas k).

\section{Materiais e Métodos}

Para se justificar uma política de PD\&I no âmbito do SUS é importante contextualizar o setor e apresentar seu impacto socioeconômico no setor Saúde. Destacase que os produtos médicos, em sua grande maioria, não são listados nas tabelas de remuneração do SUS, ou seja, o custeio da utilização destes produtos ocorre mediante o reembolso da prestação dos serviços de saúde. Entretanto, produtos que são de uso específico para um paciente (ex: aparelhos auditivos, marcapassos cardíacos implantáveis, órteses e próteses ortopédicas) são listados na Tabela de Procedimentos do SUS e, consequentemente, possuem uma rubrica específica para seu reembolso. Com isso, para um mapeamento adequado da conjuntura econômica do setor, é importante levar em consideração dados de outros órgãos de Governo além do Ministério da Saúde, a saber: Banco Central do Brasil - BaCen; Ministério do Desenvolvimento, Indústria e Comércio Exterior - MDIC; Ministério do Trabalho e Emprego - MTE; BNDES e ANVISA.

Para a caracterização dos produtos médicos abordados neste trabalho, realizou-se um levantamento das nomenclaturas utilizadas nas diversas bases de dados econômicos e governamentais, de modo a identificar o fluxo de produção, comércio e investimento. As nomenclaturas identificadas foram: Nomenclatura Comum do MERCOSUL - NCM; Classificação Nacional de Atividades Econômicas - CNAE, e no âmbito do Ministério da Saúde, onde existem cinco nomenclaturas distintas para produtos médicos, foram identificadas as nomenclaturas utilizadas pelos sistemas: DATAVISA (sistema de dados da ANVISA), SIA (Sistema de Informações Ambulatoriais), SIH (Sistema de Informações Hospitalares), GESCON (sistema de Gestão de Convênios) e SomaSUS (Sistema 
de Apoio à Elaboração de Projetos de Investimentos em Saúde).

O passo seguinte foi a realização de uma análise nas bases de dados do Ministério da Saúde, especificamente SIA e SIH, que contêm as informações sobre os atendimentos ambulatoriais e hospitalares patrocinados com recursos públicos (Oliveira, 2010). Aliado a isto foram identificadas no GESCON do MS as demandas de estados, municípios, hospitais universitários e entidades filantrópicas quanto à aquisição de equipamentos médicos mediante investimento do MS (Oliveira, 2010). Também se buscaram informações junto às instituições financeiras: dados sobre o investimento estrangeiro direto no $\mathrm{BaCen}$ e o montante captado pelas empresa no BNDES para atividades de PD\&I e investimento na infraestrutura produtiva e tecnológica. O estudo do mercado de trabalho foi avaliado por meio do Registro Anual de Informações Sociais - RAIS que é um instrumento instituído pelo MTE para consolidar registros anuais de admissões e desligamentos dos empregados dos setores público e privado. Os dados do comércio exterior, importações e exportações foram obtidos no sistema AliceWEB do MDIC (Oliveira, 2010).

Vale frisar os problemas estruturais encontrados nas diversas bases de dados dos diversos órgãos do Governo Federal o que, na grande maioria das vezes, impossibilita a obtenção e a correlação de dados das diversas bases para um mesmo ano fiscal. O panorama aqui apresentado foi fundamentado com base em uma fotografia da situação socioeconômica do SUS e das empresas do setor produtivo, em uma janela temporal compreendida entre os anos fiscais de 2002 a 2007, lembrando que neste período e nos anteriores não existiam políticas públicas para o SNIPM no âmbito do SUS. Entretanto, a inconsistência de muitas bases de dados não permitiu que, para o período em foco, se obtivessem todos os dados das bases para todos os anos fiscais abordados, o que limitou a análise conjuntural do setor em um intervalo de 60 meses e não a cada 12 meses, o que seria o usual.

A partir da análise dessas informações, foi elaborada uma proposta inicial de um programa de desenvolvimento para o setor, onde foram apontados os principais estrangulamentos e pontos a serem abordados em uma política desenvolvimentista para o setor de produtos médicos. Este documento foi discutido em uma oficina de trabalho, durante o Seminário "Pesquisa para Saúde: Desenvolvimento e Inovação para o SUS", que reuniu associações de classe do setor produtivo, academia, ICTs, agências de fomento, agências reguladoras e demais órgãos de governo relacionados com o tema. Esta oficina serviu como um instrumento destinado a validar, junto à sociedade civil e atores governamentais, as ações e estratégias de fomento ao desenvolvimento do SNIPM a serem executadas no âmbito do SUS (Brasil, 2008b).

De modo complementar, a fim de ajustar o curso da execução do Programa proposto, identificou-se os principais gargalos do setor produtivo, considerando aspectos regulatórios e de investimento interno em atividades de PD\&I, mediante a realização de uma pesquisa quantitativa com 39 empresas $(12,5 \%$ dos associados) filiadas à Associação Brasileira da Indústria de Artigos e Equipamentos Médicos, Odontológicos, Hospitalares e de Laboratórios - ABIMO. Levando em conta que a pesquisa considerou a resposta espontânea das empresas associadas e que não havia nenhum tipo de recompensa a quem se dispusesse a responder, verifica-se na literatura que este percentual é adequado, onde o melhor índice possível de resposta é $40 \%$ com média de 12 a 25\% (McDaniel e Gates, 2004).

\section{Análise dos dados setoriais}

Neste tópico são apresentados e analisados dados setoriais coletados das bases de dados descritas acima. O objetivo é quantificar e apresentar os números socioeconômicos do setor de produtos. Estes dados quantificam a importância deste setor para o país destacando-o como um importante demandante de produtos, indutor na geração de emprego especializado, renda e potencial indutor de inovação na indústria local. As terminologias balizadoras para a coleta de informações nas bases de dados são as apresentadas na Metodologia.

A Tabela 1 apresenta dados detalhados sobre cada um dos principais programas do BNDES para financiamento ao setor de produtos médicos (SEPM). Vale notar que quando o BNDES cria um programa de financiamento, o montante de recursos financeiros destinado a ele é predefinido no ato de sua criação. $\mathrm{O}$ volume de recursos decai ao longo da vigência do programa até que um novo aporte de recursos seja aprovado.

Nos recursos aprovados para o SEPM através do programa de financiamento MODERMAQ (destinado a financiar a aquisição de máquinas e equipamentos nacionais para a modernização da produção industrial), a participação do setor na captação global de recursos no programa aumentou de $0,04 \%$ (em 2005) para $0,09 \%$ (em 2009). Em termos de volume financeiro, o maior montante captado foi R\$ 1,22 milhões em 2006. No período de 2005 a 2007, observa-se outra redução no montante global de recursos em virtude da redução do volume de recursos financeiros disponíveis devido a sua captação pelo setor industrial. Apesar de, aparentemente, o montante global de recursos 
Tabela 1. Participação do setor de produtos médicos no total dos recursos aprovados por programa (modificado de Leão et al., 2008). Table 1. Participation of the medical devices sector in the total amount of approved funds by program (modified from Leão et al., 2008).

\begin{tabular}{cccccc}
\hline Ano & & Modermaq & Profarma PD\&I & Profarma produção & Progeren \\
\hline \multirow{2}{*}{2005} & Total & $\mathrm{R} \$ 2.197 .929 .972,00$ & $\mathrm{R} \$ 28.866 .288,00$ & $\mathrm{R} \$ 51.877 .280,00$ & $\mathrm{R} \$ 2.161 .736 .387,00$ \\
& SEMUS & $\mathrm{R} \$ 889.898,00$ & $\mathrm{R} \$ 0,00$ & $\mathrm{R} \$ 1.930 .677,00$ & $\mathrm{R} \$ 4.961 .265,00$ \\
& $\%$ & $0,04 \%$ & $0,00 \%$ & $3,72 \%$ & $0,23 \%$ \\
\hline \multirow{2}{*}{2006} & Total & $\mathrm{R} \$ 1.998 .126 .466,00$ & $\mathrm{R} \$ 59.722 .611,00$ & $\mathrm{R} \$ 252.623,025,00$ & $\mathrm{R} \$ 194,016.381,00$ \\
& SEMUS & $\mathrm{R} \$ 1.224 .278,00$ & $\mathrm{R} \$ 0,00$ & $\mathrm{R} \$ 14.474 .944,00$ & $\mathrm{R} \$ 2,073.290,00$ \\
& $\%$ & $0,06 \%$ & $0,00 \%$ & $5,73 \%$ & $1,07 \%$ \\
\hline \multirow{2}{*}{2007} & Total & $\mathrm{R} \$ 940.937 .659,00$ & $\mathrm{R} \$ 21,099.985,00$ & $\mathrm{R} \$ 53.188 .179,00$ & $\mathrm{R} \$ 52.702,094,00$ \\
& $\mathrm{SEMUS}$ & $\mathrm{R} \$ 828.950,00$ & $\mathrm{R} \$ 3,061,000,00$ & $\mathrm{R} \$ 7,045,000,00$ & $\mathrm{R} \$ 100,000,00$ \\
\hline
\end{tabular}

*Os dados apresentados iniciam-se no ano fiscal de 2005 porque o PROFARMA foi criado neste ano. Desta forma, para fins comparativos, os quatro programas apresentados têm seus dados avaliados para o período de 2005 a 2007.

disponíveis para financiamento do SEPM sofrer redução no MODERMAQ, isto foi compensado com a criação do programa PROFARMA destinado a financiar toda a cadeia produtiva da indústria da saúde.

Ainda na Tabela 1, observa-se que no programa de financiamento PROFARMA PD\&I (financiamento de atividades de pesquisa, desenvolvimento e inovação nas empresas), apenas em 2007 foram aprovados recursos para o SEPM, e até junho de 2008 não houve saque desses recursos. No PROFARMA Produção, pelo contrário, o montante de recursos disponíveis ao setor aumentou em $649 \%$ entre 2005 e 2006 , passando de R\$ 1,93 milhões (em 2005) para $\mathrm{R} \$ 14,47$ milhões (em 2006). Em relação à participação global no PROFARMA Produção, esta passou de 3,72 para 13,25\% no período de 2005 a 2007.

Com o Programa PROGEREN (destinado ao financiamento do capital de giro de empresas), o comportamento da participação do SEPM no montante global dos recursos disponíveis salta de $0,23 \%$ em 2005 para $1,07 \%$ em 2006. Contudo, com o advento do programa PROFARMA, o montante de recursos disponibilizados pelo PROGEREN no período de 2005 a 2007 foi reduzido significativamente entre 2005 e 2007.

Observa-se que as linhas de financiamento destinadas à atualização de plantas e processos produtivos (MODERMAQ e PROFARMA Produção) foram as que mais apoiaram as atividades do setor de produtos médicos. Em contrapartida, o PROFARMA PD\&I, destinado ao financiamento de atividades de inovação tecnológica em produtos, foi o programa de menor peso no período e pouco requerido pelo setor produtivo, demonstrando que, apesar de se constituir em um instrumento específico de financiamento de inovação no setor, ele foi pouco utilizado pelo setor produtivo no período do estudo.
Em relação ao Investimento Estrangeiro Direto (IED) no período de 2002 a 2006, de acordo com o BaCen houve incremento deste tipo de investimento na indústria de transformação brasileira como um todo. Este investimento apresentou uma trajetória de estabilidade ao longo de todo o período analisado, saindo de um patamar de US\$ 7,5 bilhões em 2002, atingindo seu pico no ano de 2004 com US\$ 10,7 bilhões e no ano de 2006, fechou com um montante de US $\$ 8,7$ bilhões de recursos aplicados. Para o segmento de produtos médicos, a trajetória deste tipo de investimento no período foi crescente (Leão et al., 2008).

Cruzando-se os dados de investimento obtidos junto ao BNDES e BaCen, obtém-se a Figura 2 que compara os recursos aplicados pelo BNDES com os recursos do IED. No acumulado do período que vai de 2002 a 2006, o montante de recursos disponibilizados pelo BNDES e de fonte estrangeira totalizaram R \$ 786,6 milhões. Desse total, os recursos do BNDES foram de R $\$ 78$ milhões, totalizando aproximadamente $10 \%$ do montante investido no setor. No entanto, a distribuição desses recursos e a participação de cada uma das fontes de investimento no setor variaram bastante ao longo do período sob análise.

Ainda segundo a Figura 2, em 2002 o total de recursos disponibilizados pelo BNDES para o setor ultrapassou o patamar de R \$ 65 milhões, sendo que $20 \%$ desses recursos provinham de linhas de financiamento do BNDES. Em 2003 e em 2004 o volume de recursos do Banco foi reduzido para números perto de $\mathrm{R} \$ 10$ milhões (em 2004, apenas $5 \%$ desses recursos eram provenientes do BNDES), ao passo que o IED alcançou as cifras de R $\$ 60$ milhões em 2003 e R\$ 174 milhões em 2004, contabilizando uma participação de $94 \%$ no total dos recursos investidos pelas duas fontes. 


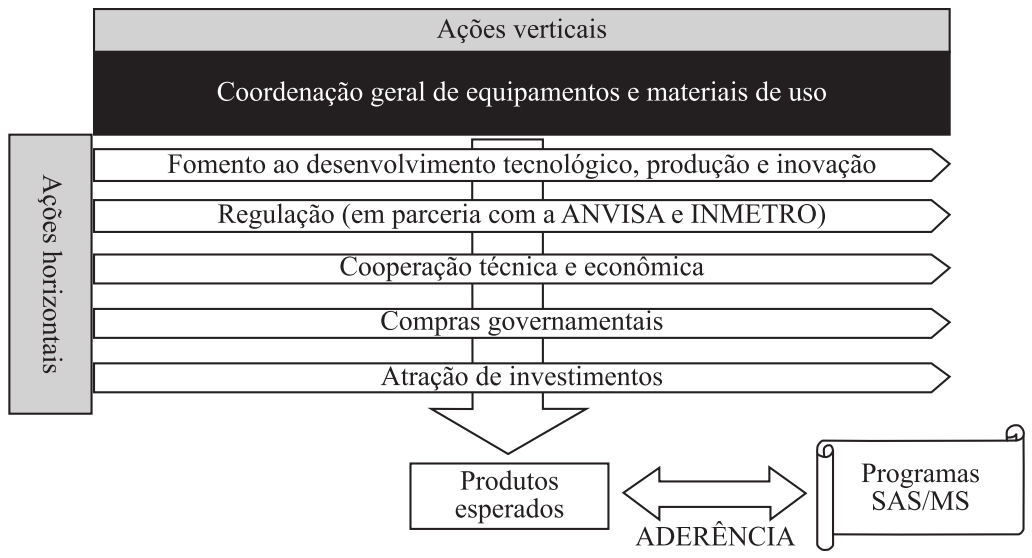

Figura 2. Evolução dos investimentos no setor (IED e BNDES) - R \$ milhões (modificado de Leão et al., 2008). Figure 2. Evolution of sectorial investments (IED and BNDES) - R\$ millions (modified from Leão et al., 2008).

A partir de 2005, com a recuperação da atenção do BNDES ao setor de produtos médicos, os recursos subiram para R \$ 13,8 milhões em 2005 e $\mathrm{R} \$ 28,8$ milhões em 2006. No entanto, os recursos externos chegaram a R \$191,8 milhões em 2005 e R \$ 229,9 milhões em 2006; nesse ano a participação dos recursos do BNDES foi de aproximadamente $11 \%$. Assim, fica claro que entre o BNDES e fontes internacionais de crédito, a principal fonte de financiamento do setor são os recursos internacionais, o que coloca o IED como um dos principais financiadores dessa atividade industrial no Brasil.

Com a leitura dos dados da RAIS/MTE pode-se perceber que a maior parte dos postos de trabalho disponibilizados tanto pelas indústrias de materiais quanto pelas de equipamento é para trabalhadores com nível médio de escolaridade, seguidos por trabalhadores com oitava série completa e ensino médio incompleto. Outra informação importante a ser destacada é que, conforme verificado na extremidade esquerda da Figura 3, de 2002 até 2005 a quantidade de empregos disponibilizados para trabalhadores com nível médio (ou educação mais avançada) tem subido, enquanto os postos de trabalho para pessoas que possuem somente até o ensino fundamental tem caído, ano após ano.

Ainda em relação ao mercado de trabalho no setor, é interessante observar a comparação dos salários médios pagos por nível de escolaridade (extremidade direita da Figura 3). Em primeiro lugar, vale dizer que em ambos os segmentos do setor (equipamentos e materiais de uso em saúde), o salário médio por nível de escolaridade se comporta de maneira esperada: quanto maior a escolaridade, maior o salário médio mensal pago aos trabalhadores. No entanto, diante destas informações, a Figura 3 mostra outra informação importante: no setor de equipamentos, as médias salariais dos trabalhadores pouco qualificados são mais altas do que no setor de materiais, enquanto que entre os trabalhadores de maior qualificação, o setor de materiais apresenta maiores médias salariais. A média do período para trabalhadores de nível superior no setor de equipamentos foi de $\mathrm{R} \$ 3,5$ mil, enquanto no setor de materiais essa média ultrapassou $\mathrm{R} \$ 4$ mil.

No que tange ao saldo global da balança comercial (Figura 4), o crescimento anual médio do déficit foi de $12,6 \%$, enquanto o crescimento do déficit de 2002 a 2006 foi de 50,7\%, passando de US\$ 752 milhões para mais de US\$1,1 bilhões. Enquanto as importações cresceram $68 \%$ de 2002 a 2006, saltando de US\$ 950 milhões para mais de US $\$ 1,5$ bilhões, as exportações expandiram de maneira mais acentuada, passando de US\$ 198 milhões em 2002 para US\$ 463 milhões em 2006. Os segmentos de radiologia e laboratório são os maiores responsáveis pelo grande aumento do déficit comercial brasileiro no setor: de um déficit de US\$ 233 milhões em 2002, o setor de laboratório atingiu a marca de US\$ 327 milhões de saldo negativo (crescimento de $40 \%$ ), enquanto o segmento de radiologia saltou da casa dos US\$ 250 milhões de déficit para aproximadamente US\$ 356 milhões (crescimento de 42\%) de 2002 a 2006 (Oliveira, 2010).

O único setor que apresenta superávit comercial sistemático ao longo de todo o período é o segmento de produtos para odontologia. O superávit comercial do setor passou de US\$ 12 milhões em 2002 para US\$ 45 milhões em 2006 - crescimento de $272 \%$. Enquanto as exportações saíram do patamar de US\$ 34 milhões em 2002 para US\$ 71 milhões em 2006, crescendo $106 \%$, as importações subiram 


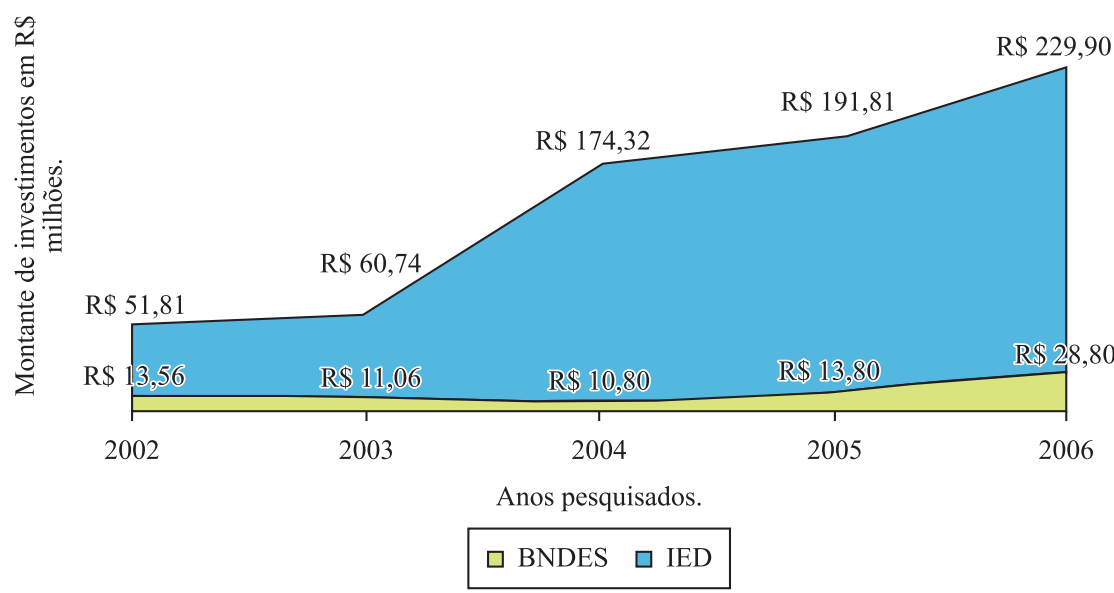

Fonte: BaCen e BNDES

Figura 3. Salário médio por faixa de escolaridade, por subsetor (Equipamentos e Materiais) (modificado de Leão et al., 2008).

Figure 3. Average salary by years of schooling, by subsector (Equipment and Materials) (modified from Leão et al., 2008).

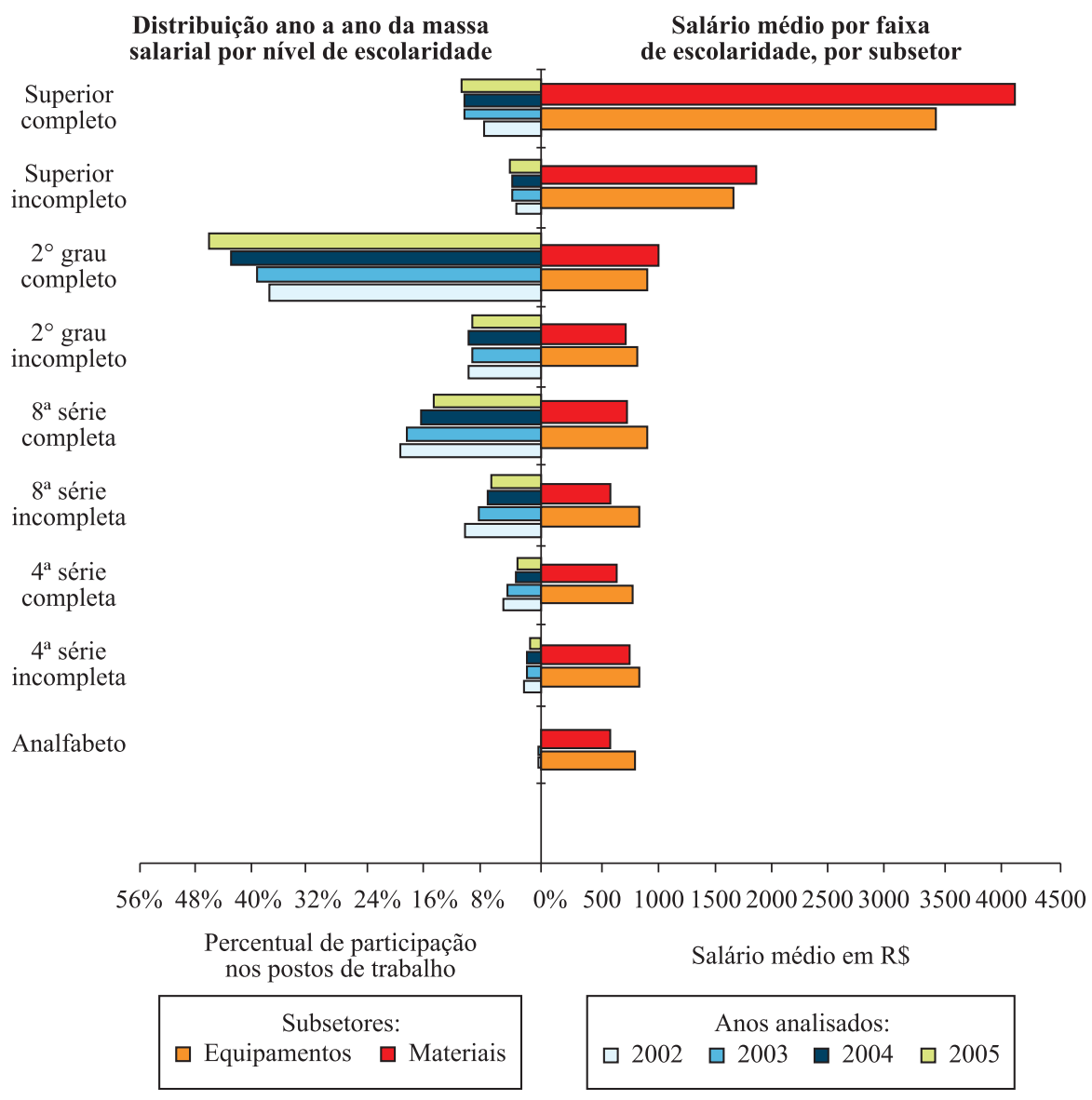

Fonte: RAIS/MTE

Figura 4. Balança comercial do setor de produtos médicos - 2006 (US\$ milhões FOB) (modificado de Leão et al., 2008). Figure 4. Balance of trade in the medical devices sector-2006 (US\$ million) (modified from Leão et al., 2008). 
apenas 17\%, partindo de US\$ 22 milhões em 2002 e chegando a pouco mais de US\$26 milhões em 2006.

A visualização gráfica deixa evidente que mesmo com elevadas taxas de crescimento das exportações e do superávit da balança comercial no segmento de produtos para odontologia, os baixos valores absolutos dificultam a superação do déficit comercial setorial. Apesar de se constituir como o único segmento superavitário da balança comercial do setor, os produtos para odontologia são os menos significativos em termos absolutos para o volume de comércio setorial.

Quanto aos gastos do SUS que geram impacto no mercado de equipamentos e materiais de uso em saúde, as informações de produção ambulatorial e hospitalar, SIA e SIH, fornecem informações sobre o consumo de alguns produtos médicos como, por exemplo, órteses e próteses ortopédicas. Verificando-se os dados do sistema Tabnet do DATASUS (Brasil, 2008a), deve-se ressaltar que os custos com próteses ortopédicas têm crescido ano após ano. Em 2002, o gasto nacional com esse tipo de produto foi da ordem de R \$ 21,9 milhões, enquanto em 2006, o dispêndio chegou ao total de R $\$ 160$ milhões. Entre 2002 e 2006 o 'grampeador linear cortante' foi o produto de maior peso no gasto total, contribuindo com $19,01 \%$ dos R \$ 21,9 milhões; em 2003 a cifra foi de R\$ 11,5 milhões, representando $8,21 \%$ do gasto no ano de 2003; em 2004 o gasto foi de R $\$ 13,3$ milhões, ou 7,8\% dos mais de R $\$ 170$ milhões daquele ano; em 2005 o custo com 'grampeador linear cortante' chegou a quase $\mathrm{R} \$ 15$ milhões, atingindo $7,67 \%$ do total; finalmente, em 2006, os gastos retrocederam ao patamar de R \$11,4 milhões, representando 7,12\% dos quase R\$ 160 milhões. Vale dizer que 2005 foi o ano da série analisada no qual o total de gastos com próteses ortopédicas atingiu um pico, chegando a cerca de R\$ 193 milhões (Leão et al., 2008).

Tabela 2. Demanda por equipamentos e materiais permanentes apresentadas no GESCON no triênio 2005-2007 (modificado de Oliveira, 2010).

Table 2. Demand for permanent equipment and materials presented in GESCON in the triennium 2005-2007 (modified from Oliveira, 2010).

Ano Valor total demandado Valor total aprovado

(R\$)

(R\$)

\begin{tabular}{llr}
\hline 2005 & $5.000 .000 .000,00 *$ & $749.553 .151,64$ \\
2006 & $5.029 .688 .178,26$ & $616.248 .621,06$ \\
2007 & $7.333 .937 .725,58$ & $1.841 .436 .910,79$ \\
Total geral aprovado & $3.207 .238 .683,49$ \\
Total geral demandado (R\$): & $13.113 .179 .055,48$ \\
Total geral demandado & $17.363 .625 .903,84$ \\
estimado (R\$):
\end{tabular}

*Estimado.
Além dos recursos gastos pelo SUS na produção ambulatorial e hospitalar, o MS também promove o mercado de equipamentos e materiais de uso em saúde por meio do Fundo Nacional de Saúde - FNS, através de convênios com diversas instituições no Brasil que prestam serviços ao SUS, financiando a compra de equipamentos de tratamento e diagnóstico.

A Tabela 2 resume a demanda por equipamentos médicos apresentada no GESCON para o triênio 2005 a 2007. Nota-se que o valor total demandado para o ano de 2005 é de cerca de $\mathrm{R} \$ 5$ bilhões. Não foi possível identificar o valor real da demanda para o ano de 2005 porque foi neste ano que o Sistema GESCON iniciou sua operação e, com isto, nem todas as propostas apresentadas ao MS foram inseridas nele. Entretanto, considerando a demanda apresentada para o ano de 2006 (R \$ 5,03 bilhões), que foi um ano eleitoral, julga-se o valor total estimado para o ano de 2005 , adequado para fins de levantamento da demanda trienal.

Ainda na Tabela 2, nota-se que em 2005 foram aprovadas propostas no valor global de R $\$ 749$ milhões, em 2006 R 616 milhões e em 2007 R \$1,8 bilhão. Para o ano de 2005, o valor total aprovado não reflete o valor global de recursos aprovados pelo MS e sim o valor para as propostas apresentadas no GESCON. Aparentemente, o montante aprovado em 2006 foi menor pelo fato de se tratar, como já mencionado, de ano eleitoral, quando os prazos para a aprovação e celebração de convênios ficam reduzidos.

Oliveira (2010) relata um levantamento realizado junto aos associados da ABIMO, onde são apresentadas informações sobre as atividades relacionadas a pesquisa e desenvolvimento de produtos por empresas nacionais. O objetivo do levantamento foi o de verificar os tipos de consultoria contratada pelas empresas em suas atividades de PD\&I, quanto do faturamento anual bruto é investido nestas atividades, o perfil das equipes internas de PD\&I, desenvolvimento de projetos cooperativos com ICTs, origem dos recursos que financiam estas atividades e os principais gargalos para a realização destas atividades. Neste artigo são destacados os dados levantados quanto à parceria empresas-ICT para o desenvolvimento de produtos e o papel da certificação de produtos como "efeito colateral" positivo do processo regulatório sobre a indução do processo de inovação no setor produtivo (Figuras 5-7).

Na Figura 5 verifica-se que 74,4\% das empresas pesquisadas apontam como no mínino "relevante" a importância de se estabelecer parcerias com ICTs para atualizar a tecnologia embarcada em seus produtos. Isto também é apontado na Figura 6, que trata do grau de relevância dada à cooperação ICT-empresa 
para o desenvolvimento de novas tecnologias. O que se observa da análise dos dois gráficos é que existe uma demanda significativa do setor produtivo por serviços tecnológicos das ICTs.

A Figura 7 demonstra que atualmente, apesar da resistência inicial na implementação da certificação de produtos, o empresariado local vê esta como uma ferramenta no mínimo "relevante" para a manutenção do seu produto no mercado, ou seja, $92,3 \%$ das empresas pesquisadas acreditam que a avaliação da conformidade confere um diferencial importante às tecnologias por elas produzidas. Desta forma, em um cenário de ampla concorrência, pode-se ter a certificação de produtos como um importante instrumento para limitar a competição predatória de produtos de qualidade, segurança e valor agregado baixos.

\section{Resultados}

O estudo realizado demonstra a importância do setor de produtos médicos não só quanto a sua relevância por fornecer tecnologias essenciais aos procedimentos médicos-assistenciais, mas também como um setor com grande potencial indutor de atividades inovadoras na produção de bens e serviços e principalmente na geração de empregos qualificados e renda.

O diagnóstico e a avaliação da atual conjuntura socioeconômicas do Sistema Nacional de Inovação em Saúde, em especial o setor de produtos médicos,

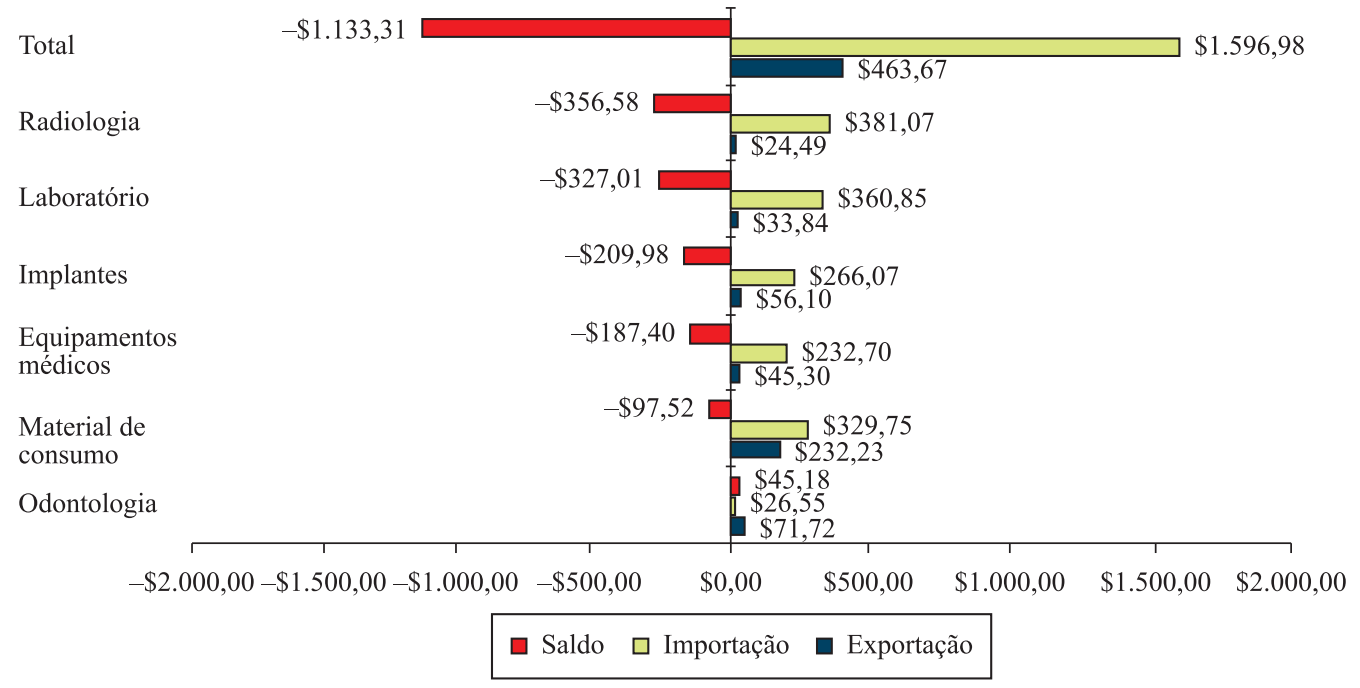

Figura 5. Grau de relevância da cooperação com ICTs para a "atualização tecnológica de produtos" nas empresas (modificado de Oliveira, 2010). Figure 5. Level of significance of the cooperation with ICTs for the "technological upgrading of products" within the companies (modified from Oliveira, 2010).

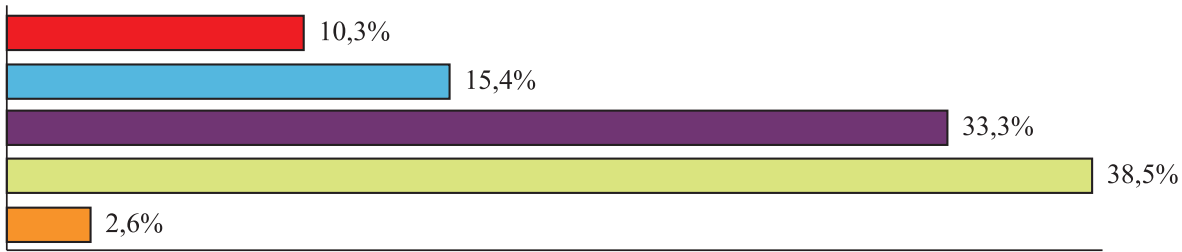

\begin{tabular}{|l|r|}
\hline Sem relevância & $10,3 \%$ \\
\hline Pouco relevante & $15,4 \%$ \\
\hline Relevante & $33,3 \%$ \\
\hline Muito relevante & $38,5 \%$ \\
\hline Extremamente relevante & $2,6 \%$ \\
\hline Total & $100 \%$ \\
\hline
\end{tabular}

Figura 6. Grau de relevância da cooperação com ICTs para o "desenvolvimento de novos produtos" (modificado de Oliveira, 2010). Figure 6. Level of significance of the cooperation with ICTs for the "development of new products" (modified from Oliveira, 2010). 


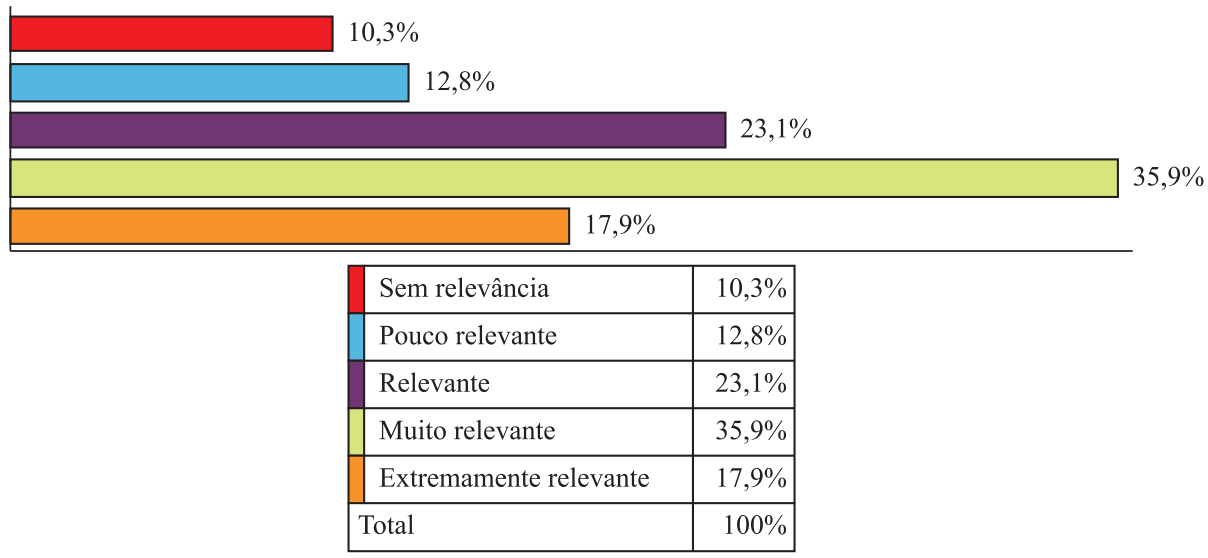

Figura 7. Relevância dada à certificação de produtos para o "aumento da competitividade de seus produtos face aos produtos importados" (modificado de Oliveira, 2010).

Figure 7. Level of significance of product certification for the "increment of product competitiveness compared to imported products" (modified from Oliveira, 2010).

realizado pela Coordenação Geral de Equipamentos e Materiais de Uso em Saúde, do Departamento do Complexo Industrial e Inovação em Saúde - CGEMS/ DECIIS avaliou dados socioeconômicos primários ou dados consolidados, disponibilizados em uma série histórica compreendida no período de 2002 a 2006.

Essas informações ajudaram a concretizar uma estratégia de desenvolvimento do SNIPM, considerando a atual realidade do setor, permitindo avaliar, de forma objetiva, a cadeia produtiva do setor de produtos médicos e delinear o Sistema de Inovação no qual o setor se insere. Como resultado concreto do estudo realizado, foi definida uma estratégia no âmbito do Ministério da Saúde denominada "Programa Nacional para Qualificação, Produção e Inovação em Equipamentos e Materiais de Uso em Saúde no Complexo Industrial da Saúde" (Brasil, 2008c) (Portaria MS/GM n ${ }^{\circ} 375 / 2008$ ).

As ações estabelecidas no Programa ocorrem de forma integrada e alinhada com os programas do Ministério da Saúde, estabelecendo princípios e eixos estratégicos contemplados na Política Nacional de Ciência, Tecnologia e Inovação em Saúde e aliando as demandas tecnológicas e prioridades do SUS com as demandas dos mercados alvo do setor produtivo.

As linhas de ação propostas consistem em ações horizontais do Programa cujos temas centrais e abordagens são apresentadas na Figura 8. A principal premissa para a definição das estratégias do Programa e para a definição de projetos e ações é que estes estejam em consonância e aderentes aos programas do Ministério, em especial os programas e projetos desenvolvidos e executados pela Secretaria de Atenção à Saúde (Oliveira et al., 2008).
A primeira estratégia do programa consiste no fomento a projetos tecnológicos e a atividades voltadas à produção e inovação. Com esta abordagem busca-se estabelecer procedimentos e programas para a transferência de tecnologias estratégicas ao SUS, com base em suas demandas tecnológicas. Além disso, a estratégia visa consolidar os atuais centros de referência e induzir a implantação de novos centros de PD\&I no país. Ademais, a estratégia de fomento não ignora questões regulatórias e a preocupação da consolidação de conteúdo tecnológico, não só no setor industrial quanto nos centros de referência. Outro ponto a ser destacado é que esta estratégia não buscou definir ou propor novos instrumentos legais para a contratação de projetos tecnológicos, ou seja, os instrumentos utilizados são aqueles já existentes no arcabouço jurídico do país.

A questão da articulação regulatória também foi prevista pelo Programa. Não é possível falar em desenvolvimento produtivo e inovação de produtos e processos em um setor regulado sem que haja uma definição clara de seus mecanismos regulatórios. Isto é especialmente importante para os instrumentos regulatórios utilizados em política industrial e como barreira a produtos de baixa qualidade. Quinze anos após a implantação da certificação no setor, é notório e constatado pela Pesquisa de Inovação Tecnológica - PINTEC do IBGE que a certificação induziu, compulsoriamente, o investimento em inovações incrementais em produtos e processos produtivos.

A primeira abordagem da terceira estratégia do Programa objetiva estabelecer cooperação técnica entre o MS e ICTs brasileiras com instituições 


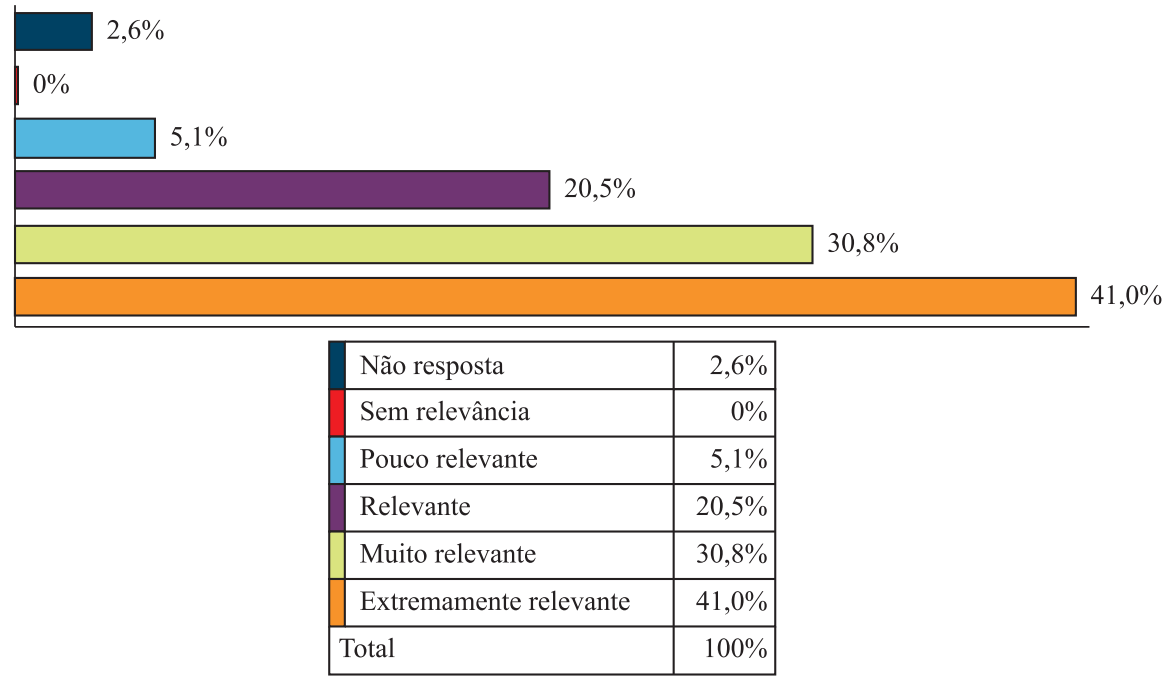

Figura 8. Ações Horizontais do Programa da Portaria MS 375/2008 (modificado de Oliveira et al., 2008).

Figure 8. Horizontal actions of the Program from Portaria MS 375/2008 (modified from Oliveira et al., 2008).

internacionais visando a formação de recursos humanos e transferência de tecnologia. Como os ativos tecnológicos utilizados pelo SNIPM de um setor podem estar localizados dentro ou fora do país, a cooperação técnica com instituições científicas no exterior pode catalisar o processo de desenvolvimento de tecnologias estratégicas, encurtando o tempo necessário para se alcançar o domínio tecnológico sobre determinado produto. Dados do Banco Mundial mostram que a cooperação técnica internacional entre instituições científicas de países desenvolvidos e aqueles em desenvolvimento, pode promover a equiparação tecnológica e fortalecer o desenvolvimento de atividades inovadoras (Wagner et al., 2001).

Em relação à quarta estratégia (atração de investimentos), os estudos setoriais apontaram que o Brasil apresenta um forte histórico de receptor de Investimento Estrangeiro Direto (IED) no setor de produtos médicos. Para se criar um ambiente favorável para investimentos no país é preciso uma forte determinação do Estado para, além de manter o curso de reformas macroeconômicas, desenvolver e aperfeiçoar os marcos regulatórios e coordenar políticas voltadas para ações microeconômicas. Trata-se, portanto, de um tema que exige do Estado a criação de condições, senão ideais, pelo menos atrativas, à luz de vários elementos técnico-econômicos, políticos e sociais. A atração e a promoção de investimentos precisam ser acompanhadas da infraestrutura adequada, da necessária estabilidade política e econômica da região e do país, da infraestrutura social e da localização geográfica relativa ao mercado que se pretende atingir.

\section{Discussão}

A evolução e a diversificação da tecnologia nas últimas décadas proporcionaram novos campos de atuação para a engenharia biomédica, como o desenvolvimento de equipamentos para uso médico e a gestão de tecnologias médico-assistenciais. Nos anos 80 a atuação da engenharia biomédica foi estendida para setores da saúde pública e saúde coletiva, dando-se início ao que hoje se denomina de Engenharia de Sistemas de Saúde (Programa..., 2010). Esta ampliação de competência ocorreu naturalmente, mas catalisada, principalmente, pela escassez de recursos frente às necessidades ilimitadas da sociedade, o que no setor saúde ainda é mais evidente. A limitação de recursos faz com que cada vez mais se procure utilizá-los de modo otimizado, em especial os recursos de capital. $\mathrm{Na}$ estrutura socioeconômica em que vivemos, o capital não possui somente a função de facilitar o processo de transações entre os elementos da sociedade, mas serve também como importante agente no processo de produção dos bens e serviços sendo transacionados, e na distribuição destes produtos entre a população.

No contexto do SNIPM, o conhecimento científico e tecnológico e a capacidade de inovação são as principais ferramentas para o sucesso econômico consistente e autossustentado e que, na atual conjuntura mundial, está cada vez mais apoiado no desenvolvimento tecnológico com base no conhecimento científico e na capacidade tecnológica e industrial. O país que não detiver estas competências, ainda que disponha do capital, da mão-de-obra e das matérias-primas, estará condenado a gravitar em torno dos países 
mais competentes. Nesta abordagem de qualidade e competitividade, a questão técnica-regulatória torna-se, também, uma questão estratégica e fundamental no incremento da competitividade do SNIPM.

As peculiaridades deste setor fazem com que uma proposta indutora para seu desenvolvimento não possa adotar modelos unicamente econômicos sem que se avalie o contexto regulatório, científico e as demandas tecnológicas do Sistema Único de Saúde. Do mesmo modo que a engenharia clínica pondera questões como tipos e riscos de tecnologias médicas, fluxos e processos administrativos do serviço médico na aplicação de ferramentas econômico-gerenciais, ela pode usar de seu conhecimento específico para olhar o Sistema de Inovação sob um prisma que permite correlacionar os dados socioeconômicos setoriais com os gargalos tecnológicos, estruturais e regulatórios observados no âmbito de suas atividades. Em outras palavras, acredita-se que da mesma forma que a engenharia clínica é capaz de transpor ferramentas administrativo-gerenciais e técnicas de engenharia econômica para o contexto hospitalar, ela pode contribuir no caminho inverso, ajudando na definição de estratégias para o incremento tecnológico e desenvolvimento do Sistema Nacional de Inovação de Produtos Médicos.

Com o cenário apresentado, sugere-se que os esforços iniciais em ciência, tecnologia e inovação no SNIPM devam ser orientados pelo SUS em função das demandas de bens e serviços econômicos e das necessidades sociais e regionais do país. A definição de temas estratégicos deve compor políticas setoriais de modo a permitir uma articulação estruturada e vinculações entre os diversos atores e instituições dos SNIs.

\section{Conclusão}

Verifica-se que a estratégia proposta corrobora e entra em consonância com as demais propostas desenvolvimentistas instituídas pelo Governo Federal. A proposição foi oficializada pelo Ministério da Saúde e publicada em 29/02/2008, instituindo o "Programa Nacional para Qualificação, Produção e Inovação em Equipamentos e Materiais de Uso em Saúde no Complexo Industrial da Saúde" (Brasil, 2008c) no âmbito do Sistema Único de Saúde, mediante a Portaria MS/GM n ${ }^{0} 375 / 2008$. Tem-se o Programa apresentado como uma ferramenta destinada à indução do desenvolvimento do SNISPM de modo a fortalecer e modernizar o setor de produtos médicos, visando a ampliação da capacidade inovadora das empresas e mudança do seu patamar competitivo a partir das demandas tecnológicas do SUS e de iniciativas de articulação de ações públicas e privadas destinadas a promover o desenvolvimento da base tecnológica no país.

Desta forma, acredita-se que com o Programa proposto, o MS deixa a posição de coadjuvante no SNIPM, ou seja, de mero demandante de tecnologia, para ser indutor, fomentador e articulador do Complexo Industrial da Saúde, propiciando e induzindo o desenvolvimento setorial a partir de suas demandas.

\section{Referências}

Albuquerque EM, Cassiolato JE. As especificidades do sistema de inovação do setor saúde. Revista de Economia Política. 2002; 22(4):134-51.

Arruda M, Velmulm R, Hollanda S. Inovação tecnológica no Brasil: a indústria em busca da competitividade global. São Paulo: ANPEI; 2006. 117p.

Bobbie B. Health Technology assessment: challenges and solutions for medical devices. Canada: Cook Medical; 2010.

Brasil. Lei $\mathrm{n}^{\circ}$ 9.279, 14 de maio de 1996. Regula direitos e obrigações relativos à propriedade industrial. Diário Oficial da República Federativa do Brasil, Brasília, DF, n. 93, 15 mai 1996. Seção 1, p. 8353-66

Brasil. Lei no 9.609, 19 de fevereiro de 1998. Dispõe sobre a proteção da propriedade intelectual de programa de computador, sua comercialização no País, e dá outras providências. Diário Oficial da República Federativa do Brasil, Brasília, DF, n. 36, 20 fev 1998. Seção 1, p. 1-3.

Brasil. Lei no ${ }^{\circ} 10.973$, de 2 de dezembro de 2004. Dispõe sobre incentivos à inovação e à pesquisa científica e tecnológica no ambiente produtivo e dá outras providências. Diário Oficial da República Federativa do Brasil, Brasília, DF, n. 233, 3 dez 2004. Seção 1, p. 2-4.

Brasil. Lei $\mathrm{n}^{\circ} 11.196$, de 21 de novembro de 2005 . Institui o Regime Especial de Tributação para a Plataforma de Exportação de Serviços de Tecnologia da Informação - REPES, o Regime Especial de Aquisição de Bens de Capital para Empresas Exportadoras - RECAP e o Programa de Inclusão Digital e dá outras providências. Diário Oficial da República Federativa do Brasil, Brasília, DF, n. 223, 22 nov 2005. Seção 1, p. 1-12.

Brasil. Ministério da Saúde. Portaria Conjunta SNVS/SAS $n^{\circ} 1$, de 17 de maio de 1993. Dispõe sobre a classificação de produtos correlatos para efeito de registro no Ministério da Saúde. Diário Oficial da República Federativa do Brasil, Brasília, DF, n. 98, mai 1993. Seção 1, p. 7042-5.

Brasil. Ministério da Saúde. Departamento de Informática do SUS - DATASUS. Sistema TABNET. Sítio eletrônico. 2008a [acesso em 2008 fev.]. Disponível em: tabnet.datasus.gov. $\mathrm{br} /$ tabnet/tabnet.htm

Brasil. Ministério da Saúde. Secretaria de Ciência, Tecnologia e Insumos Estratégicos. Pesquisa para Saúde: desenvolvimento e inovação para o SUS: relatório final. Brasília: Ministério da Saúde, 2008b. 
Brasil. Ministério da Saúde. Portaria MS 375, de 29 de fevereiro de 2008. Institui, no âmbito do Sistema Único de Saúde - SUS, o Programa Nacional para Qualificação, Produção e Inovação em Equipamentos e Materiais de Uso em Saúde no Complexo Industrial da Saúde. Diário Oficial da República Federativa do Brasil, Brasília, DF, n. 41, 29 fev 2008c. Seção 1, p. 119.

Freeman C. Japan: A new national system of innovation? In: Technical Change and Economic Theory. London: Pinter Publishers; 1988. p. 341-8.

Gadelha CAG. O complexo industrial da saúde e a necessidade de um enfoque dinâmico na economia da saúde. Ciência \& Saúde Coletiva. 2003; 8(2):521-35. http://dx.doi.org/10.1590/ S1413-81232003000200015

Leão R, Oliveira EJV, Albornoz LJC. Estudo setorial - Setor de equipamentos e materiais de uso em saúde. Brasília: Ministério da Saúde; 2008.

McDaniel C, Gates R. Pesquisa de marketing. São Paulo: Thomson Learning; 2004. p. 562.

Oliveira EJV, Leão R, Button VLSN. Nova abordagem para o Sistema Nacional de Inovação de Produtos Médicos. In: CBEB 2008: Anais do $21^{\circ}$ Congresso Brasileiro de
Engenharia Biomédica; 2008 Nov 16-20; Salvador, Brasil. Salvador; 2008. p. 335-8.

Oliveira EJV. Engenharia clínica aplicada à definição e implementação de uma proposta desenvolvimentista para o Sistema Nacional de Inovação de Produtos Médicos [dissertação]. Campinas: Universidade Estadual de Campinas; 2010.

Programa de Engenharia Biomédica - PEB. UFRJ [Internet]. 2010 [acesso em 2010 maio]. Disponível em: http://www.peb.ufrj.br/pesquisa.htm

Rosenberg N. Inside the black box: technology and economics. Cambridge: University Press; 1982. 320p.

Wagner CS, Brahmakulam I, Jackson B, Wong A, Yoda T. Science and technology collaboration: building capacity in developing countries? [Internet]. RAND: Arlington; 2001. 2001 [cited 2012 Jan]. 102 p. Available from: http://www.rand.org/pubs/monograph_reports/2005/ MR1357.0.pdf.

World Health Organization - WHO. Medical device regulations: Global overview and guiding principles. Genebra; 2003. 43p.

\section{Autores}

Eduardo Jorge Valadares Oliveira

Departamento de Engenharia Biomédica - DEB, Centro de Engenharia Biomédica - CEB, Faculdade de Engenharia Elétrica e de Computação - FEEC, Universidade Estadual de Campinas - UNICAMP, Campinas, SP, Brasil. Departamento de Computação - DC, Centro de Ciências e Tecnologia - CCT, Núcleo de Tecnologias Estratégicas em Saúde - NUTES, Universidade Estadual da Paraíba - UEPB, Campina Grande, PB, Brasil.

Vera Lúcia da Silveira Nantes Button*

Departamento de Computação - DC, Centro de Ciências e Tecnologia - CCT,

Núcleo de Tecnologias Estratégicas em Saúde - NUTES, Universidade Estadual da Paraíba - UEPB,

Rua Baraúnas, 351, Bairro Universitário, CEP 58429-500, Campina Grande, PB, Brasil. 